\title{
ẢNH HƯỞNG CỦA THAM SỐ BÃO TỚI NƯớC DÂNG SAU KHI BÃO ĐỔ BỘ TẠI VEN BIỂN BẮC BỘ
}

\author{
Phạm Trí Thức ${ }^{*}$, Nguyễn Bá Thủy², Đỗ Đình Chiến ${ }^{3}$, Đinh Văn Mạnh ${ }^{4}$, \\ Phạm Khánh Ngọc ${ }^{2}$, Nguyễn Văn Mơi ${ }^{4}$
}

Tóm tắt: Trong nghiên cưu này, ảnh hưởng trường gió, khi áp và tốc độ di chuyển của bão tới nuớc dâng do bão ở ven biển Bắc Bộ được phân tích theo kết quả mô phỏng bằng mô hình số trị tích hợp SuWAT (Surge Wave and Tide) đối với nước dâng trong bão Kalmaegi-14 đổ bộ vào Quảng Ninh tháng 9/2014. Bão Kalmaegi-14 đổ bộ vào ven biển Quảng Ninh tối ngày 15 tháng 9 năm 2014 đã gây hiện tượng nước dâng sau khi bão đổ bộ. Anh huởng của truờng gió, khi áp truớc và sau khi bão đổ bộ cũng nhu tốc độ di chuyển và cuờng độ bão được phân tích. Kết quả cho thấy, truờng gió mạnh sau bão là nguyên nhân gây hiện tương nước dâng sau khi bão đổ bộ tại ven biển Bắc Bộ. Khi vận tốc di chuyển của bão tăng thì nước dâng tại Cưa Ông giảm, trong khi đó tại Hòn Ngu nước dâng tăng. Nước dâng tại Hòn Dấu đạt giá trị lớn nhất với truờng hợp tốc độ di chuyển của bão Kalmaegi14 chậm hơn 1 giờ so với thực tế. Nước dâng tại 3 trạm tăng theo vận tốc gió, tuy nhiên trạm Hòn Ngu có tốc độ tăng lớn hơn. Độ lớn nước dâng giảm khi khíáp trong bão tăng nhưng mức độ tăng tại 3 trạm khác nhau, trạm Cưa Ông tăng chậm hơn. Kết quả nghiên cứu sẽ rất hũu ích trong công tác cảnh báo, dụ báo nước dâng do bão tại khu vực.

Từ khóa: Nước dâng sau bão, SuWAT, tốc độ di chuyển, cường độ bão.

Ban Biên tập nhận bài: 20/3/2020 Ngày phản biện xong: 15/4/2020 Ngày đăng bài: 25/04/2020

\section{1. Đặt vấn đề}

Những nhân tố chính ảnh hưởng tới nước dâng do bão bao gồm: Các tham số bão (quỹ đạo, vận tốc gió, bán kính gió mạnh, khí áp tâm bão), thủy triều, sóng biển và địa hình khu vực (độ sâu và hình dạng đường bờ). Thông thường nước dâng bão xuất hiện và đạt cực đại tại thời điểm bão đổ bộ vào bờ. Tuy nhiên, trong nhiều trường hợp đã ghi nhận hiện tượng nước biển dâng tại thời điểm trước (fore-runner surge) và sau khi bão đổ bộ (after-runner surge). Trong đó, hiện tượng nước dâng sau bão đổ bộ thường kéo dài trong hàng chục giờ, đã gây nhiều thiệt hại do tính bất ngờ chưa dự báo được. Một số trường hợp nước dâng sau bão điển hình như: Bão Vera-

${ }^{1} H o c$ viện Hải quân, Quân chủng Hải quân

${ }^{2}$ Trung tâm Dư báo Khí tương Thủy văn Quốc gia

${ }^{3}$ Viện Khoa học Khí tượng Thủy văn và Biến đổi khi hạu

${ }^{4}$ Viện co học, viện Hàn lâm Khoa học và Công nghẹ Việt Nam

Email: pthucacademy@yahoo.com.vn
86, Dinah-87, Caitlin-91, Mireille-91, Rusa-02, Maemi-03, Megi-04, Songda-04 đổ bộ vào ven biển miền Trung Nhật Bản [7]; Bão Iker-08 đổ bộ vào Bắc tiểu bang Texas [5]; Bão Becky-90, Kalmaegi-14, Mirinae-16 đổ bộ vào ven biển Bắc Bộ của Việt Nam [3]. Tùy thuộc vào khu vực cũng như đặc trưng bão, nguyên nhân gây nước dâng sau bão có thể do: Tác động của hình thế gió, khí áp trước và sau khi bão đổ bộ, thủy triều, sóng biển và hiệu ứng bơm Ekman tại lưu vực [7]. Do vậy, nghiên cứu nguyên nhân và cơ chế gây nước dâng sau bão cần thiết phải thực hiện cho từng cơn bão và khu vực cụ thể, sau đó đề suất cải tiến công nghệ dự báo phù hợp, nhất là trong bối cảnh biến đổi khí hậu khi được nhận định sẽ có nhiều cơn bão mạnh/siêu bão với diễn biến bất thường ảnh hưởng tới ven bờ Việt Nam.

Với hiện tượng nước dâng sau bão, một số ít nghiên cứu đã được thực hiện cho cơn bão cụ thể. Sooyoul Kim và cộng sự (2014) đã sử dụng mô hình tích hợp SuWAT đánh giá hiện tượng nước dâng xuất hiện sau khi bão Songda-04 đổ bộ vào ven bờ Tottori-Nhật Bản theo nhiều phương án 
tính toán (sử dụng trường gió, khí áp từ mô hình bão giải tích, mô hình số trị khí tượng; có và không xét tới ảnh hưởng của thủy triều, sóng và hiệu ứng bơm Ekman) và đưa ra kết luận rằng hiệu ứng bơm Ekman là nguyên nhân chính gây hiện tượng nước dâng sau bão, và trường gió, khí áp từ mô hình dự báo số trị khí tượng cho kết quả phù hợp hơn mô hình bão giải tích. Sau đó, quy trình dự báo hiện tượng nước dâng xuất hiện sau bão đã được xây dựng cho khu vực ven bờ Tottori-Nhật Bản [7]. Nghiên cứu của Kenedy và cộng sự (2011) về hiện tượng nước dâng trước xuất hiện trước khi bão Iker-08 đổ bộ vào Bắc tiểu bang Texas cho thấy ngoài hiệu ứng bơm Ekman, địa hình khu vực có ảnh hưởng mạnh đến cơ chế gây nước dâng trước và sau khi bão đổ bộ [5]. Những nghiên cứu này cũng chỉ ra rằng, hiện tượng nước dâng sau bão cần phải nghiên cứu chi tiết cho từng cơn bão cụ thể.

Bão Kalmaegi đổ bộ vào ven biển Quảng Ninh ngày 15 tháng 9 đã gây hiện tượng nước biển dâng kéo dài hàng chục giờ tại ven biển Bắc Bộ sau khi bão đổ bộ vào bờ. Cơ chế của hiện tượng nước biển dâng sau bão Kalmaegi đã được phân tích trong nghiên cứu của Nguyễn Bá Thủy và cộng sự (2014) [2], [3]. Trong nghiên cứu này ảnh hưởng của trường gió, khí áp trước và sau khi bão đổ bộ và các tham số bão (vận tốc di chuyển và cường độ) tới nước dâng do bão ở ven biển Bắc Bộ được phân tích theo kết quả mô phỏng bằng mô hình số trị tích hợp SuWAT để làm rõ vai trò của các tham số bão đến nước dâng sau bão, góp phần nâng cao chất lượng trong công tác cảnh báo, dự báo nước dâng bão tại khu vực nghiên cứu.

\section{Khu vực và phương pháp nghiên cứu}

\subsection{Khu vục nghiên cúu}

Khu vực vịnh Bắc Bộ được bao bọc bởi Việt Nam và Trung Quốc, có diện tích khoảng $126.250 \mathrm{~km}^{2}$, chiều ngang nơi rộng nhất khoảng $320 \mathrm{~km}$ (176 hải lý) và nơi hẹp nhất khoảng $220 \mathrm{~km}$ (119 hải lý). Chiều dài bờ biển phía Việt
Nam khoảng $763 \mathrm{~km}$ được xác định từ Móng CáiQuảng Ninh đến Quảng Trị như trên Hình 1

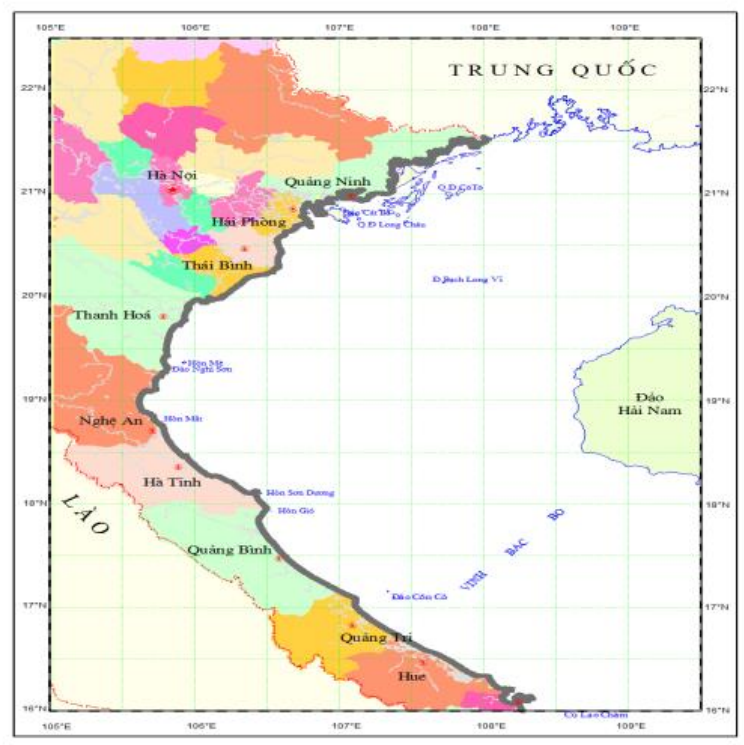

Hình 1. Khu vực nghiên cứu vịnh Bắc Bộ

Mùa bão dọc ven biển khu vực này thường bắt đầu từ tháng 6 và kết thúc vào tháng 10 . Các cơn bão mạnh ở Việt Nam thường đổ bộ vào khu vực này và gây nước dâng lớn như: bão Dan (1989) gây nước dâng cao 3,6m tại Cửa Việt, bão Kelly (1981) gây nước dâng cao nhất tại Lệch GépNghệ An 3,3m, bão Ceicil (1985) gây nước dâng 2,5m tại Thừa Thiên Huế, bão Frankie (1986) gây nước dâng cao tới 3,2m tại Tiền Hải-Thái Bình, bão Niki (1996) gây nước dâng 3,1m tại Hải HậuNam Định...

\subsection{Phương pháp nghiên cúu}

Để mô phỏng nước dâng trong bão Kalmaegi, mô hình tích hợp thủy triều, sóng biển và nước dâng do bão được áp dụng (SuWAT) bao gồm 2 mô hình thành phần là mô hình sóng dài dựa trên hệ phương trình nước nông phi tuyến 2 chiều có xét đến nước dâng do ứng suất bức xạ sóng và mô hình SWAN [4] để tính sóng. Hệ phương trình cơ bản của mô hình nước nông phi tuyến 2 chiều được mô tả như sau:

$$
\frac{\partial \eta}{\partial t}+\frac{\partial M}{\partial x}+\frac{\partial N}{\partial y}=0
$$

$$
\frac{\partial M}{\partial x}+\frac{\partial}{\partial x}\left(\frac{M^{2}}{d}\right)+\frac{\partial}{\partial y}\left(\frac{M N}{d}\right)+g d \frac{\partial \eta}{\partial x}=f N-\frac{1}{\rho_{w}} d \frac{\partial P}{\partial x}+\frac{1}{\rho_{w}}\left(\tau_{S}^{x}-\tau_{b}^{x}+F_{x}\right)+A_{h}\left(\frac{\partial^{2} M}{\partial x^{2}}+\frac{\partial^{2} M}{\partial y^{2}}\right)
$$




$$
\frac{\partial N}{\partial t}+\frac{\partial}{\partial y}\left(\frac{N^{2}}{d}\right)+\frac{\partial}{\partial x}\left(\frac{N M}{d}\right)+g d \frac{\partial \eta}{\partial y}=-f M-\frac{1}{\rho_{w}} d \frac{\partial P}{\partial y}+\frac{1}{\rho_{w}}\left(\tau_{S}^{y}-\tau_{b}^{y}+F_{y}\right)+A_{h}\left(\frac{\partial^{2} N}{\partial x^{2}}+\frac{\partial^{2} N}{\partial y^{2}}\right)
$$

Trong đó: $\eta$ là mực nước bề mặt; $M, N$ là thông lượng trung bình theo độ sâu, theo hướng $\mathrm{x}$ và $\mathrm{y}$; $\mathrm{f}$ là tham số Coriolis; $\mathrm{P}$ là áp suất khí quyển; $\mathrm{d}$ là độ sâu tổng cộng $\mathrm{d}=\eta+\mathrm{h}$ (với h là độ sâu mực nước tĩnh); $A_{h}$ là hệ số khuếch tán rối theo phương ngang; $\rho_{\mathrm{w}}$ là mật độ nước; $\tau_{\mathrm{b}}, \tau_{\mathrm{s}}$ là ứng suất ma sát đáy và bề mặt; $\mathrm{F}_{\mathrm{x}}, \mathrm{F}_{\mathrm{y}}$ là ứng suất sóng được bổ sung để xét nước dâng do sóng, được tính từ mô hình SWAN. Cơ sở lý thuyết, phương pháp giải và điều kiên biên, ban đầu đã được trình bày chi tiết trong [1], [6], [8]. Trường gió và khí áp được lấy từ mô hình WRF với độ phân giải $7 \mathrm{~km}$.

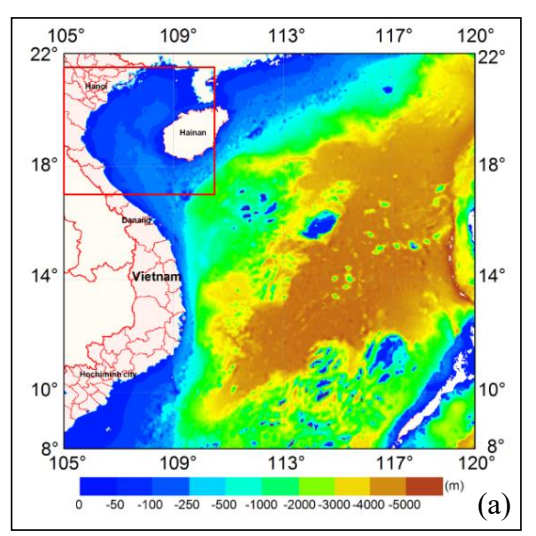

\section{Kết quả tính toán và thảo luận}

\subsection{Miền tính và lưới tính cho mô hình}

Để mô phỏng nước dâng trong bão Kalmegi, mô hình SuWAT được thiết kế trên lưới vuông và lồng 3 lớp như trên Hình 2. Hệ thống lưới lồng được xây dựng cho khu vực nhằm 3 mục đích: (1) có thể chi tiết hóa sự biến đổi phức tạp của địa hình khu vực ven bờ nhằm tăng độ chính xác của mô phỏng, (2) tăng khả năng tính nước dâng do ứng suất sóng, (3) giảm thời gian tính toán (phục vụ trong dự báo nghiệp vụ). Miền tính và lưới tính cho các khu vực được mô tả chi tiết trên Bảng 1 dưới đây:

Hình 2. Trường độ sâu và miền tính của 3 lưới lồng:

(a) Lưới tính Biển Đông (D1), (b) Lưới tính khu vục ven biển Bắc bộ (D2),

(c) Lưói chi tiết cho ven biển Quảng Ninh-Ninh Bình (D3)

Bảng 1. Miền tính và độ phân giải lưới tính ven biển Bắc bộ

\begin{tabular}{llcc}
\hline Lưới & \multicolumn{1}{c}{ Miền tính } & $\begin{array}{c}\text { Số điểm tính theo } \\
\text { kinh \& vĩ tuyến }\end{array}$ & $\begin{array}{c}\text { Độ phân giải } \\
{[\Delta \mathrm{x} \times \Delta \mathrm{y}]}\end{array}$ \\
\hline $\mathrm{D} 1$ & $105^{\circ} \mathrm{E}-120^{\circ} \mathrm{E}, 8^{\circ} \mathrm{N}-22^{\circ} \mathrm{N}$ & $226 \times 211$ & $7400 \times 7400$ \\
$\mathrm{D} 2$ & $105.0^{\circ} \mathrm{E}-110.5^{\circ} \mathrm{E}, 16.0^{\circ} \mathrm{N}-21.5^{\circ} \mathrm{N}$ & $181 \times 241$ & $1850 \times 1850$ \\
$\mathrm{D} 3$ & $106.0^{\circ} \mathrm{E}-107.5^{\circ} \mathrm{E}, 20.0^{\circ} \mathrm{N}-21.0^{\circ} \mathrm{N}$ & $181 \times 121$ & $925 \times 925$ \\
\hline
\end{tabular}

\subsection{Hiện tượng nước dâng sau bão}

\section{Kalmaegi đổ bộ vào bò̀}

Bão Kalmaegi-14 có quỹ đạo như trên Hình $3 \mathrm{a}$, hình thành ngoài khơi phía đông Philippines vào trưa ngày 12/9/2014 từ một vùng áp thấp nhiệt đới. Trong quá trình di chuyển về phía đất liền Việt Nam, cường độ bão đã có lúc mạnh trên cấp 13. Tâm bão đi vào ven biển Quảng Ninh khoảng 21 giờ ngày 16/9/2014, là lúc thủy triều xuống thấp nhất trong ngày và sau đó tiếp tục đi sâu vào đất liền, suy yếu dần thành áp thấp nhiệt đới. Bão Kalmaegi-14 gây ra gió mạnh cấp 9-10, giật cấp 11-12 cho ven biển Quảng Ninh và Hải Phòng. Vào sáng và trưa ngày 17/9 tức là sau khoảng 10 giờ bão đổ, khu vực ven biển Hải Phòng-Quảng Ninh đã xuất hiện nước biển dâng cao kèm theo những con sóng cao từ $3-4 \mathrm{~m}$ gây ngập lụt một số khu vực trũng, như tại thị trấn 
Đồ Sơn-Hải Phòng (Hình 3b). Đây là một tình hủy triều cao nhất của năm. huống khá bất ngờ vì không phải là thời điểm

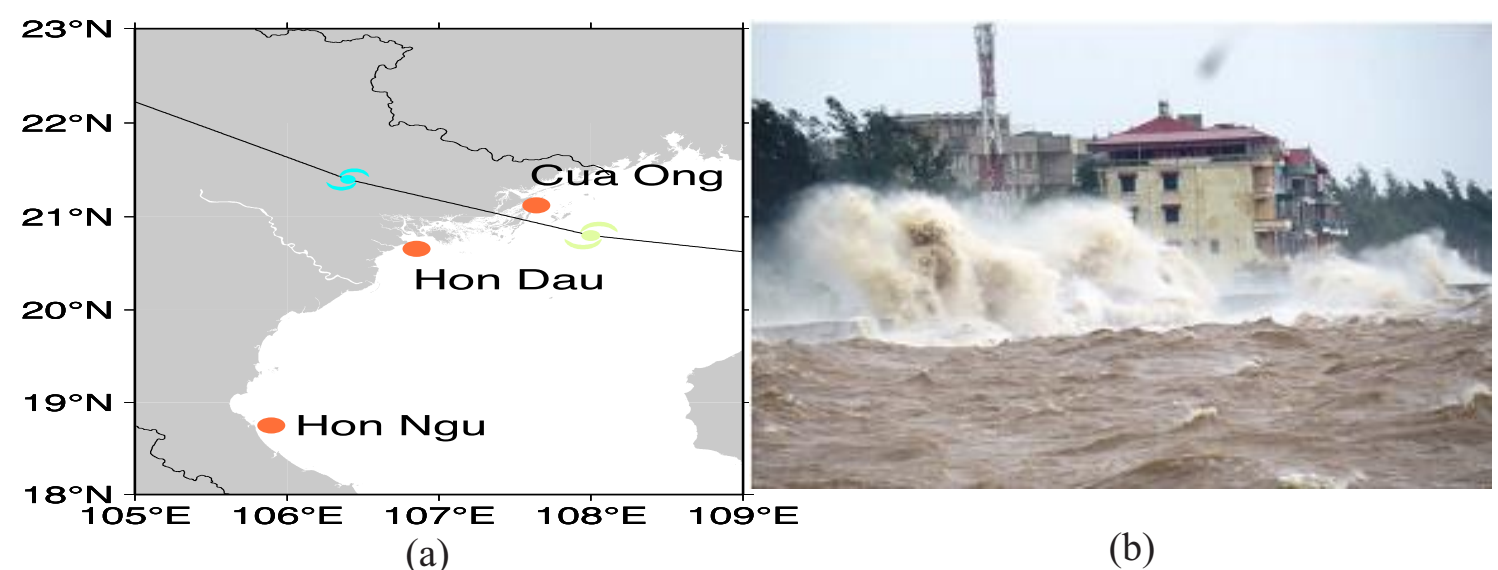

Hình 3. (a) So đồ đường đi của bão Kalmaegi-14, (b) Sóng lớn và ngập lụt ven bò̀ nước dâng bão kết hợp với triều cuờng tại Đồ Sơn - Hải Phòng sau khi bão Kalmaegi-14 đổ bộ

Trên Hình 4 là dao động mực nước tổng cộng, thủy triều và nước dâng (mực nước tổng cộng-thủy triều) tại Hòn Dấu (Hình 4a) và Hòn Ngư (Hình 4b). Kết quả phân tích cho thấy nước dâng do bão Kalmaegi-14 có một số điểm khác thường bởi sau khoảng 3 giờ bão đổ bộ nước dâng mới đạt trên $50 \mathrm{~cm}$ và thời gian tồn tại nước dâng kéo dài tới hơn hơn 12 giờ (trạm Hòn Dấu, Hình 4a). Tại trạm Hòn Ngư, nơi rất xa vị trí bão

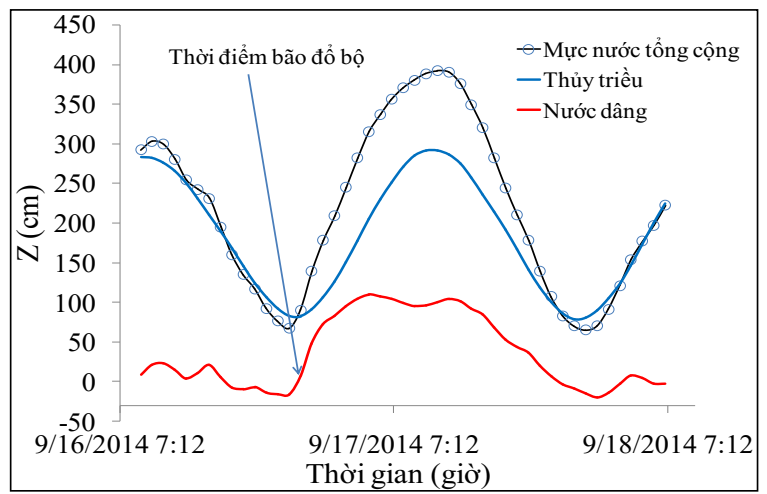

(a) đổ bộ, cũng ghi nhận nước dâng xuất hiện sau khi bão đổ bộ 6 giờ và nước dâng cao $0,5 \mathrm{~m}$ kéo dài trong 7 giờ (Hình 4b). Trên hình 5 thể hiện mối liên hệ giữa nước dâng do bão với vận tốc gió (Hình 5a) và khí áp (Hình 5b). Kết quả cho thấy nước dâng do bão tại Hòn Dấu có tương quan với vận tốc gió nhiều hơn so với khí áp thể hiện sự trùng pha của nước dâng và vận tốc gió như trên Hình 5a.

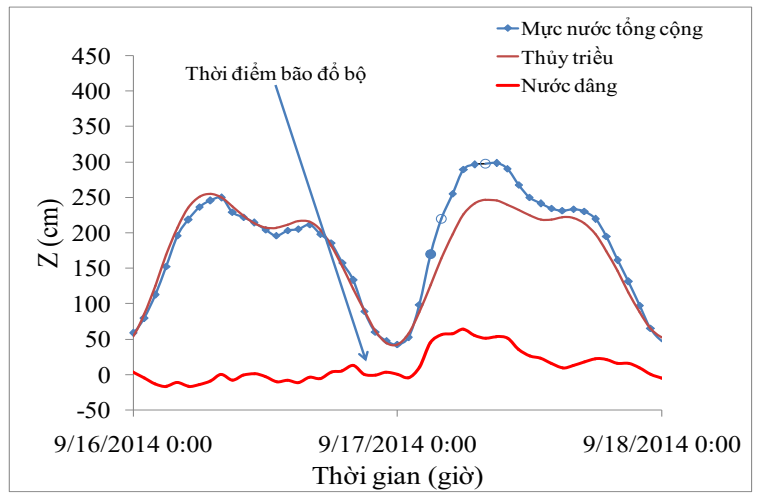

(b)

Hình 4. Dao động của mưc nước tổng cộng, thủy triều và nước dâng sau bão tại trạm Hòn Dấu (a) và Hòn Ngu (b) trước và sau khi bão Kalmaegi-14 đổ bộ vào bò̀

\subsection{Ainh hưởng của trừ̀ng gió trước và sau}

\section{khi bão đổ bộ tới nước dâng do bão}

Để đánh giá vai trò của trường gió trước và sau khi bão đổ bộ tới nước dâng do bão tại ven biển Bắc Bộ, phương án tính nước dâng nhưng không xét tới ảnh hưởng của gió sau khi bão đã đổ bộ được thực hiện, tức là trường gió được giả định ở trạng thái thời tiết bình thường với vận tốc gió gán bằng "0" (WRF-no wind, trên Hình $6 \mathrm{a}$ và Hình $6 \mathrm{~b}$ ). Kết quả mô phỏng cho thấy, tại Hòn Dấu độ lớn và thời gian tồn tại nước dâng nhỏ hơn khi không sử dụng trường gió sau khi bão đổ bộ. Trong khi đó, tại Hòn Ngư mức độ giảm của nước dâng lớn nhất nhỏ hơn so với tại 
Hòn Dấu. Như vậy, có thể thấy rằng trường gió mạnh sau khi bão đổ bộ là nguyên nhân gây

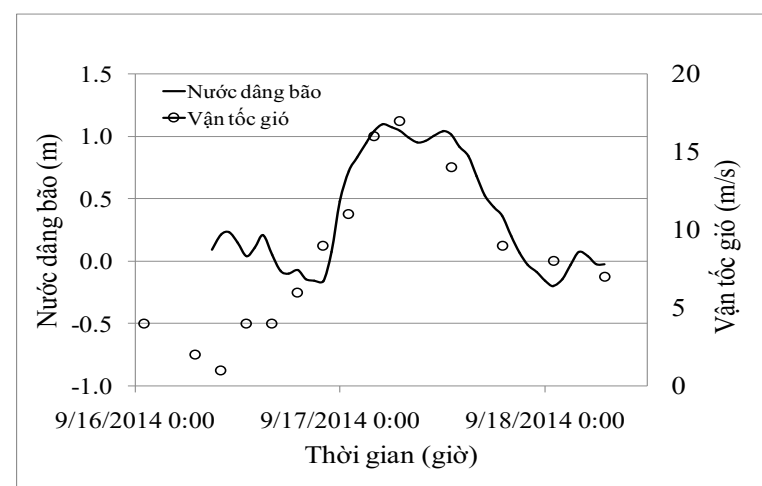

(a) nước dâng sau bão tại Hòn Dấu.

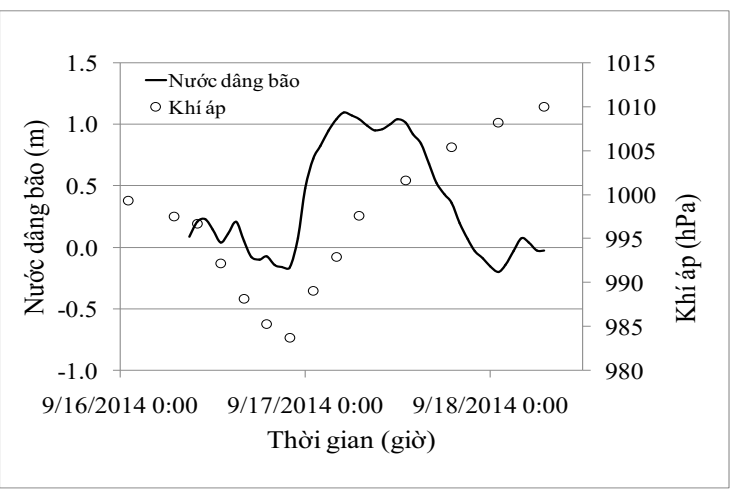

(b)

Hình 5. Dao động của nước dâng bão với vận tốc gió (a) và khí áp (b) tại trạm Hòn Dấu trong bão Kalmaegi-14

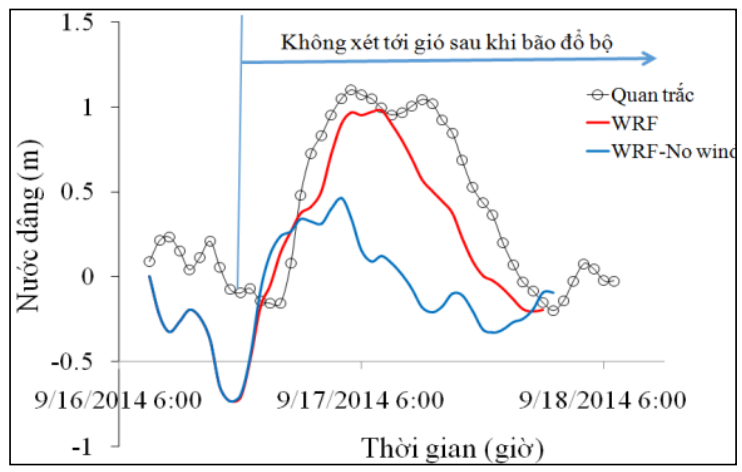

(a)

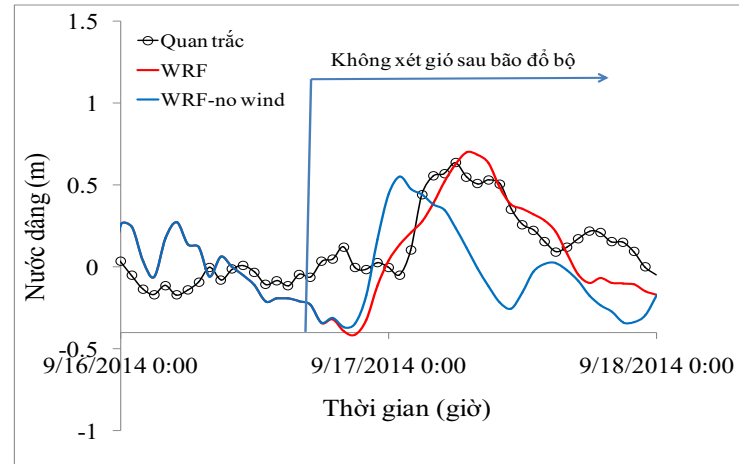

(b)

Hình 6. So sánh nước dâng tính toán và quan trắc tại Hòn Dẩu (a) và Hòn Ngu (b) trong bão Kalmaegi-14 theo phuơng án xét đầy đủ truờng gió, khi áp và chỉ xét truớc khi bão đổ bộ

\subsection{Anh hưởng của khí áp tâm bão tới nước dâng}

Ảnh hưởng của khí áp tâm bão tới nước dâng được thực hiện với trường hợp quỹ đạo và các tham số bão khác như tốc độ di chuyển, vận tốc gió được giữ nguyên nhưng thay đổi khí áp tâm bão theo hướng tăng (cường độ bão yếu hơn) và giảm (cường độ bão mạnh hơn) so với khí áp thực tế của bão Kalmaegi-14 trong khoảng từ $15 \mathrm{hPa}$ đến $+15 \mathrm{hPa}$. Biến thiên nước dâng lớn nhất theo sự thay đổi của khí áp tâm bão so với thực tế tại Cửa Ông, Hòn Dáu và Hòn Ngư trên Hình $7 \mathrm{a}$ cho thấy độ lớn nước dâng tại 3 trạm giảm khi khí áp tâm bão tăng. Trên Hình $7 b$ là tỷ lệ nước dâng lớn nhất $\left(Z_{\max } / Z_{\max }(\right.$ thực tế) $)$ tại Cửa Ông, Hòn Dấu và Hòn Ngư với sự thay đổi của khí áp tâm bão so với thực tế. Kết quả cho thấy xu thế giảm của nước dâng dâng lớn nhất khi khí áp tâm bão tăng lên, tuy nhiên mức độ giảm tại Hòn Ngư nhanh hơn tại Hòn Dấu. 


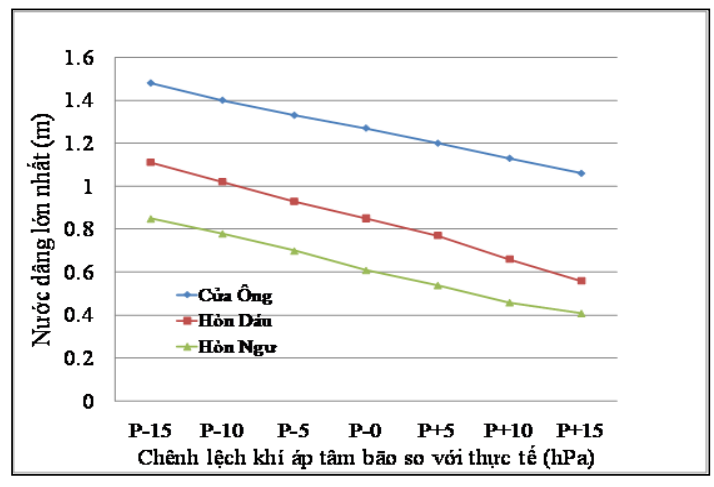

(a)

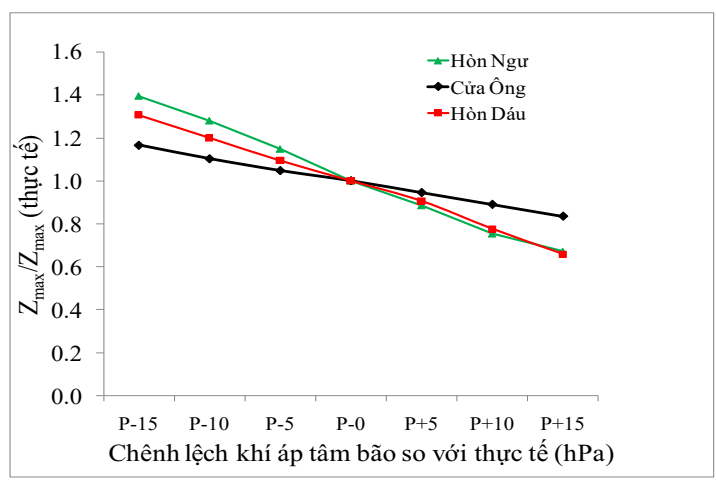

(b)

Hình 7. Sự thay đổi của nước dâng lớn nhất (a) và tỷ lệ nước dâng lớn nhất so với thực tế (b) tại Cửa Ông, Hòn Dáu và Hòn Ngu trong trương hơp thay đổi khí áp tâm bão Kalmaegi-14

\subsection{Anh hưởing của tốc độ di chuyển của bãa}

Để đánh giá ảnh hưởng của tốc độ di chuyển của bão tới nước dâng do bão, bão Kalmaegi-14 được giữ nguyên quỹ đạo và cường độ nhưng thay đổi vận độ di chuyển chậm và nhanh hơn trong khoảng từ $-15 \mathrm{~km} / \mathrm{h}$ đến $+15 \mathrm{~km} / \mathrm{h}$ giờ so với vận tốc di chuyển thực tế. Trên Hình $8 \mathrm{a}-\mathrm{c}$ là biến trình nước dâng do bão tại Cửa Ông, Hòn Dấu và Hòn Ngư với các trường hợp vận tốc di chuyển thực tế, nhanh hơn $5 \mathrm{~km} / \mathrm{h}(\mathrm{W}+5)$ và chậm hơn $5 \mathrm{~km} / \mathrm{h}$ (W-5) hơn so với thực tế. Kết quả cho thấy, tại Cửa Ông và Hòn Dấu nước dâng bão cao hơn với trường hợp tốc độ di chuyển của bão chậm hơn $5 \mathrm{~km} / \mathrm{h}$ giờ, trong khi đó tại Hòn Ngư nước dâng lớn hơn với trường hợp bão di chuyển nhanh hơn so với thực tế $5 \mathrm{~km} / \mathrm{h}$ giờ. Kết quả tính toán nước dâng lớn nhất tại Cửa Ông, Hòn Dấu và Hòn Ngư với sự thay đổi của tốc độ di chuyển của bão trên Hình $8 \mathrm{~d}$ cho thấy khi tốc độ di chuyển của bão càng chậm thì nước dâng tại Cửa Ông càng lớn và ngược lại đối với trạm Hòn Ngư. Trong khi đó với trạm Hòn Dấu nước dâng bão tăng khi tốc độ di chuyển chậm và đạt giá trị lớn nhất tại với trị số tốc độ di chuyển của bão chậm hơn so với thực tế $5 \mathrm{~km} / \mathrm{h}$ và sau đấy nước dâng lớn nhất giảm dần.

\subsection{Anh hưởng của vận tốc gió tới nước dâng}

Ảnh hưởng của vận tốc gió tới nước dâng được thực hiện với trường hợp quỹ đạo và các tham số bão khác như tốc độ di chuyển, khí áp tâm bão được giữ nguyên nhưng thay đổi vận tốc gió trong bão theo hướng tăng (cường độ bão yếu hơn) và giảm (cường độ bão mạnh hơn) so với khí áp thực tế của bão Kalmaegi-14 trong khoảng từ $-6 \mathrm{~m} / \mathrm{s}$ đến $+6 \mathrm{~m} / \mathrm{s}$. Biến thiên nước dâng lớn nhất theo sự thay đổi của vận tốc gió trong bão so với thực tế tại Cửa Ông, Hòn Dấu và Hòn Ngư trên Hình $9 \mathrm{a}$ cho thấy độ lớn nước dâng tại 3 trạm tăng khi vận tốc gió trong bão tăng. Trên Hình $9 \mathrm{~b}$ là tỷ lệ nước dâng lớn nhất $\left(Z_{\max } / Z_{\max }(\right.$ thực tế)) tại Cửa Ông, Hòn Dấu và Hòn Ngư với sự thay đổi của vận tốc gió trong bão so với thực tế. Kết quả cho thấy nước dâng bão tại 3 trạm đều tăng khi vận tốc gió tăng nhưng tốc độ tăng tại Hòn Ngư nhỏ hơn so với Cửa Ông và Hòn Dấu. 


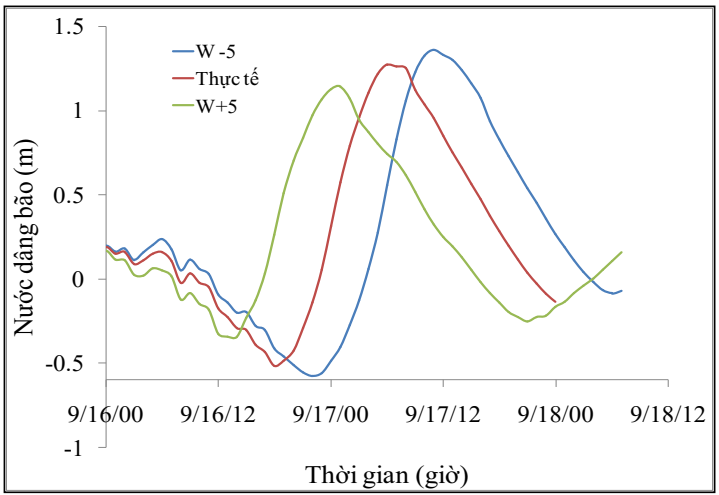

(a)

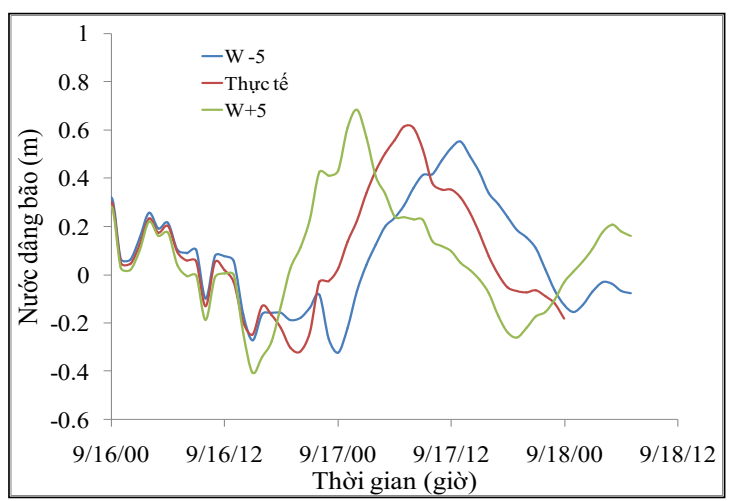

(c)

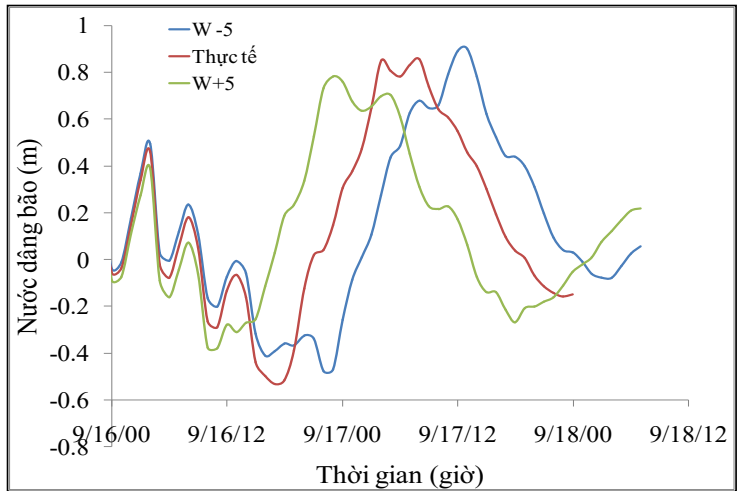

(b)

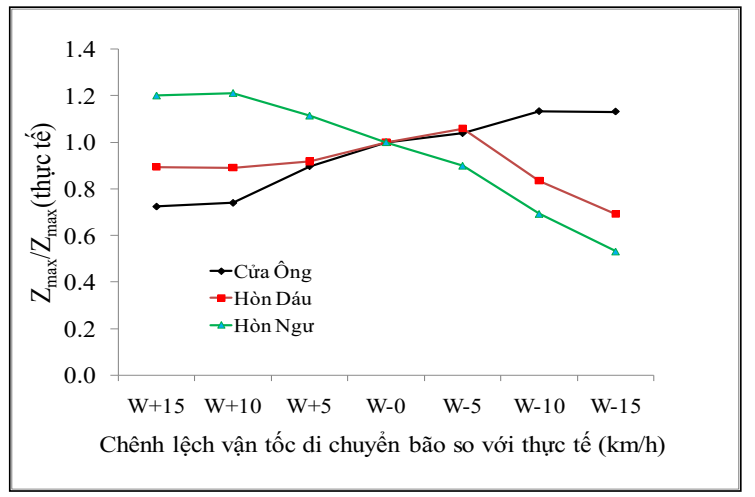

(d)

Hình 8. Diễn biến nước dâng tại Của Ông (a), Hòn Dấu (b) và Hòn Ngu (c) với truờng hợp vận tốc di chuyển của bão nhanh và chậm hơn so với thực tế $5 \mathrm{~km} / \mathrm{h}$ giờ; (d) Nước dâng lớn nhất tại Cửa Ông, Hòn Dấu và Hòn Ngu với sụ thay đổi vận tốc di chuyển của bão

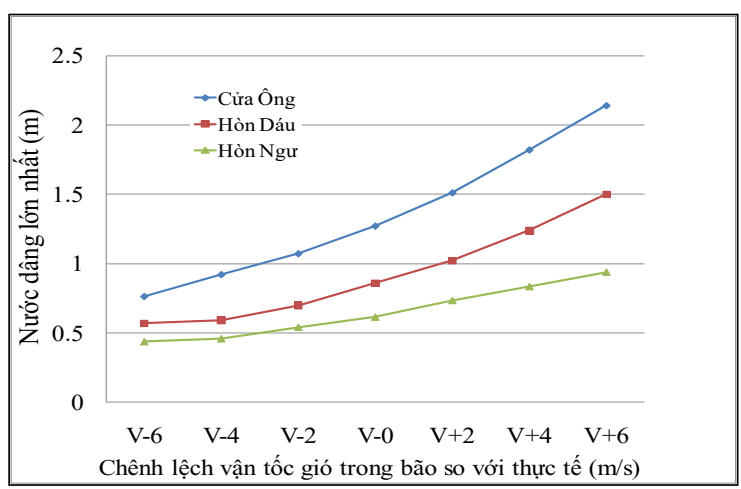

(a)

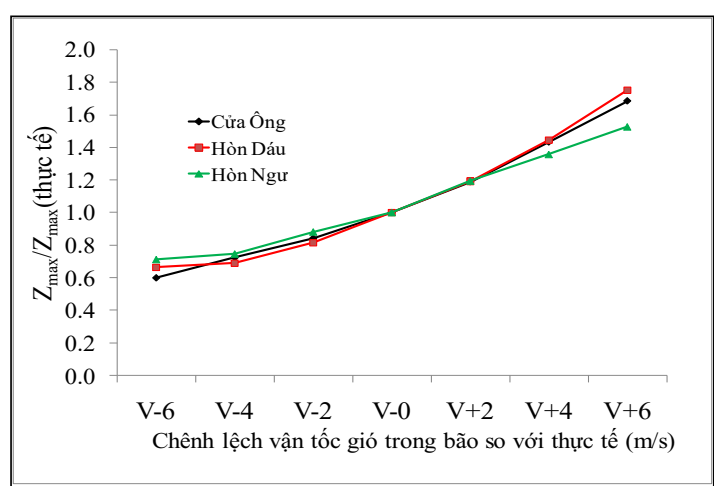

(b)

Hình 9. Sự thay đổi của nước dâng lớn nhất (a) và tỷ lệ nước dâng lớn nhất so với thực tế (b) tại Của Ông, Hòn Dấu và Hòn Ngu trong truờng hợp thay đổi vận tốc gió trong bão Kalmaegi

Kết quả phân tích ảnh hưởng của cường độ bão ở trên cho thấy nước dâng tại Cửa Ông bị chi phối bởi vận tốc gió nhiều hơn so với khí áp tâm bão và trường hợp ngược lại đối với trạm Hòn Ngư, nước dâng bị chi phối bởi khí áp nhiều hơn so với vận tốc gió trong bão. Nhận định này được minh họa trên Hình 10, ở đó là tỷ lệ nước dâng lớn nhất với phương án tính nước dâng gây

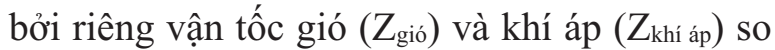
với nước dâng lớn nhất do đồng thời cả gió và

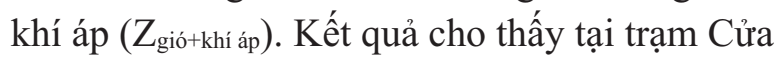
Ông, nước dâng gây bởi gió chiếm tới 78\% nước 


\section{BÀI BÁO KHOA HỌC}

dâng tổng cộng (do gió và khí áp), trong khi đó hơn so với vận tốc gió trong bão. tại Hòn Ngư, tỷ lệ nước dâng gây bởi khí áp lớn

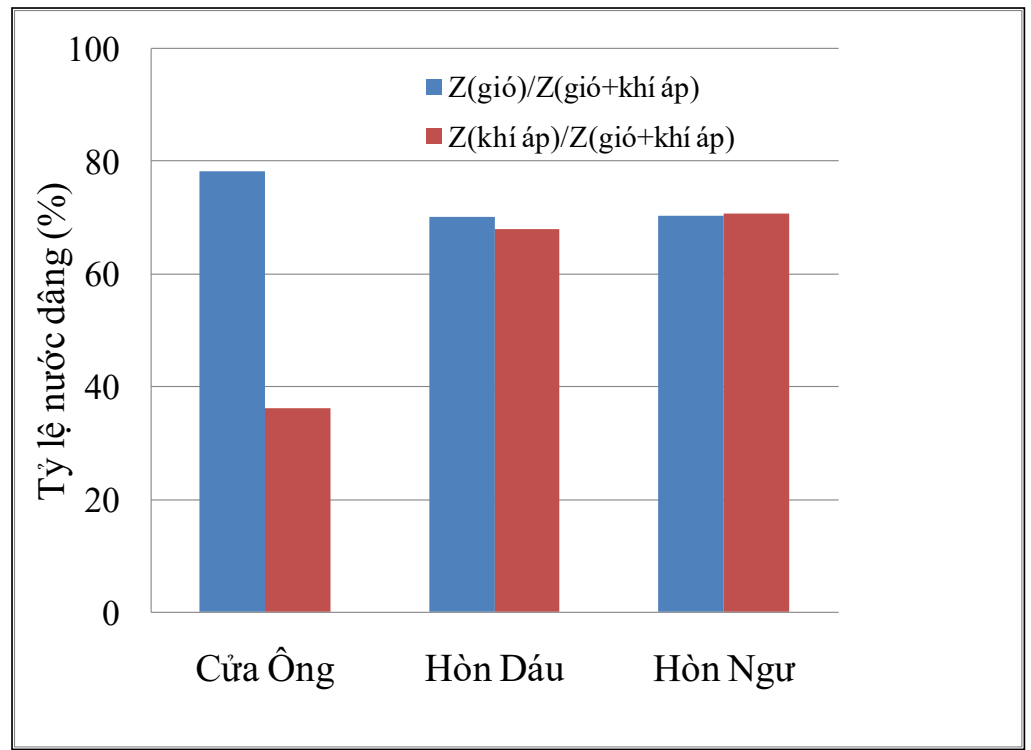

Hình 10. Tỷ lệ nước dâng lớn nhất với phuoong án tính chỉ xét tới gió ( $\left.Z_{g i o}\right)$

và khí áp $\left(Z_{k h i a ́ p}\right)$ với phuoong án tính đồng thời cả gió và khí áp tại Cửa Ông, Hòn Dấu và Hòn Ngu trong bão Kalmaegi-14

\section{Kết luận}

Trong nghiên cứu này, ảnh hưởng trường gió, khí áp và tốc độ di chuyển của bão tới nước dâng do bão ở ven biển Bắc Bộ được phân tích theo kết quả mô phỏng bằng hình SuWAT nước dâng trong bão Kalmaegi-14 đổ bộ vào Quảng Ninh tháng 9 năm 2014. Kết quả cho thấy, trường gió mạnh sau bão là nguyên nhân gây hiện tượng nước dâng sau khi bão đổ bộ tại ven biển Bắc Bộ. Khi vận tốc di chuyển của bão tăng lên thì nước dâng tại Cửa Ông giảm, trong khi đó tại Hòn Ngư tăng. Nước dâng tại Hòn Dấu đạt giá trị lớn nhất với trường hợp tốc độ di chuyển của bão chậm hơn 5 giờ so với thực tế. Nước dâng tại 3 trạm tăng theo vận tốc gió, tuy nhiên trạm Hòn ngư có tốc độ tăng lớn hơn. Độ lớn nước dâng giảm khi khí áp trong bão tăng nhưng mức độ tăng tại 3 trạm khác nhau, trạm Cửa Ông tăng chậm hơn. Nước dâng tại Cửa Ông bị chi phối bởi vận tốc gió nhiều hơn so với tại Hòn Ngư.

Lời cảm ơn: Nghiên cứu này được tài trợ bởi Bộ Tài nguyên và Môi truoòng trong đề tài "Nghiên cứu co sỏ khoa họ và xây dụng quy trình xác địinh cấp độ rủi ro thiên tai do bão, áp thấp nhiệt đới và nước dâng do bão; mã số TNMT.2017.05.05" và Quỹ phát triển khoa học và công nghệ quốc gia (NAFOSTED) trong đề tài mã số 105.06-2017.07. Tập thể tác giả xin chân thành cảm ơn.

\section{Tài liệu tham khảo}

1. Chiến, Đ.Đ., Thủy, N. B., Sáo, N.T., Thái, T.H., Kim, S. (2014), Nghiên cứu tương tác sóng và nước dâng do bão bằng mô hình số trị. Tạp chí Khí tượng Thủy văn, 647, 19-24.

2. Thủy, N.B., Cường, H.Đ., Hưởng, N.V., Tiến, D.Đ. (2018), Đánh giá nguy co bão và nước dâng do bão tại ven biển Việt Nam. Tạp chí khí tượng thủy văn, 684, 29-36.

3. Nguyễn Bá Thủy (2017), Nghiên cưu cơ chế gây nước dâng sau khi bão đổ bộ tại ven biển Bắc $B \hat{o}$. Tạp chí Khoa học và Công nghệ Biển, 17 (4B), 208-216.

4. Delf University of Technology (2004), SWAN Cycle III Verion 40.31, User Guide. Delf. 
5. Kennedy, A.B., Gravois, U., Zachry, B.C., Westerink, J.J., Hope, M.E., Dietrich, J.C., Powell, M.D., Cox, A.T., Luettich, R. A. Jr., Dean, R.G. (2011), Origin of the Hurricane Ike forerunner surge. Geophysical research letters, 38, L08608.

6. Kim, S.Y., Yasuda, T., Mase, H. (2010), Wave set-up in the storm surge along open coasts during Typhoon Anita. Coastal Engineering, 57 (7), 631-642.

7. Kim, S.Y.; Matsumi, Y.; Yasuda, T., Mase, H. (2014), Storm surges along the Tottori coasts following a typhoon. Ocean Engineering, 91, 133-145.

8. Thuy, N.B., Kim, S., Dang, V.H., Cuong, H.D., Wettre, C., Hole, L.R. (2017), Assessment of Storm Surge along the coast of Central Vietnam. Journal of Coastal Research, 33, 518-530.

\title{
EFFECTS OF STORM PARAMETERS ON STORM SURGES AFTER STORM HIT THE NORTHERN COAST \\ Pham Tri Thuc', Nguyen Ba Thuy², Do Dinh Chien ${ }^{3}$, Dinh Van Manh ${ }^{4}$, Pham Khanh Ngoc ${ }^{2}$, Nguyen Van $\mathrm{Moi}^{4}$ \\ ${ }^{1}$ Naval Academy-Naval Service \\ ${ }^{2}$ National Center for Hydro-Meteorological Forecasting \\ ${ }^{3}$ Vietnam Institute of Meteorology, Hydrology and Environment \\ ${ }^{4}$ Institute of Mechanics-VAST
}

\begin{abstract}
In this study, the influence of wind field, barometric pressure and the speed of storm movement to storm surge in the Northern coastal region were analyzed according to simulation results using an integrated numerical model SuWAT calculate storm surge in the typhoon Kalmaegi (9/2014). Typhoon Kalmaegi hit Quang Ninh coastal area in the evening of 15/9/2014, causing afterstorm surge. The influence of wind field, barometric pressure before and after the Typhoon landing as well as movement speed and storm intensity were analyzed. The results showed that the strong wind field after the typhoon was the cause of the after-storm surge when typhoons hit the Northern coast. When the movement speed of storm increases, the seawater rise at Cua Ong station decreases, while of Hon Ngu station increases. Storm surge at Hon Dau station reached the highest value with the case that the speed of typhoon Kalmaegi was slower than 1 hour compared to reality. Seawater level rise at 3 stations increased with wind speed, however, at Hon Ngu station had a higher growth rate. Magnitude of rising water decreases when the pressure in the storm increases but the level increases at 3 different stations, Cua Ong station increases more slowly. The research results will be very useful in warning and forecasting storm surge in the area.
\end{abstract}

Keywords: After-storm surges, SuWAT, speed of movement, storm intensity. 